ISBN: 978-1-948012-12-6 New Materials and Intelligent Manufacturing (NMIM)

\title{
EFFECT OF OILING CONTROL ON PRODUCTION COST AND QUALITY OF CARBON FIBRE PRECURSOR
}

\author{
Yu Bo', Qiao Ruibo ${ }^{*}$ \\ ${ }^{1}$ College of Information \& Control Engineer, Jilin Institute of Chemical Technology, Chengde Street,Jilin City, China \\ ${ }^{2}$ School of Mechanical Electronic \& Information Engineering China University of Mining and Technology,Beijing Beijing, China \\ *Corresponding Author Email: Ruiboq@126.com
}

This is an open access article distributed under the Creative Commons Attribution License, which permits unrestricted use, distribution, and reproduction in any medium, provided the original work is properly cited

\section{ARTICLE DETAILS}

\section{Article History:}

Received 26 June 2018 Accepted 2 July 2018

Available online 1 August 2018

\section{ABSTRACT}

In the production of carbon fibre industry, oiling of carbon fibre precursor can impart fibre smoothness, antistatic property, and bundling property, and also allows the precursors to have sufficient high temperature resistance, fibre splitting, and melting resistance; therefore, the oiling control has a crucial effect on the production cost and quality of carbon fibre precursors. This paper discusses the oiling methods of carbon fibre precursors by using the oil roller and circulation pump of oil groove, besides, the defects of these two methods in practice were also analysed. Thus, the oiling methods above were further improved and changed to be the oiling tank for oil groove. Finally, it is concluded that the excellent oil control method, combined with good finish oil proportioning and experienced operator control, can depress the adverse effects of oil on carbon fibre precursors, solve the oil defects, and reliably improve the performance of carbon fibre precursors; the reliable oil control enables the oil to achieve an ideal oiling effect, ensuring the stability, continuity and homogeneity of various indicators in the production of carbon fibre precursors.

\section{KEYWORDS}

Carbon fibre precursor, oil, product cost, quality

\section{INTRODUCTION}

With more understanding for the production process of carbon fibre precursors, familiarity with the production process, and continuous exploration and research, it has been found that oiling control has a crucial effect on the production cost and quality of carbon fibre precursors. Based on a study, the oiling of carbon fibre precursors can impart fibre smoothness, antistatic property, and bundling property, and also allows the precursors to have sufficient high temperature resistance, fibre splitting property, and anti-melting property [1-4]. In the carbon fibre industry production, there are a large number of precursors for carbon fibre spinning, so the strict control of even oiling is required, and the current oiling is uniformly controlled to be between $0.5 \%$ and $1.8 \%$. If the oil concentration is too high, excessive powder might be easily generated during the carbonization of carbon fibre precursors, causing the blocking of related equipment in the carbonization furnace, and further affecting the fibre strength; then it shall fail to meet the requirements for use. According to a study, if it is too low, the ash content of the carbon fibre shall be high, and the fibre strength be decreased, thus, the spin ability of carbon fibre precursor production is reduced, affecting the yield of carbon fibre precursors, and resulting in high production control costs [5].
Therefore, the research and improvement of carbon fibre precursor oiling equipment and control process have become the key focus in the production process. In this paper, the effect of oil control on the production cost and quality of carbon fibre precursors is analysed [6].

\section{OILING METHOD OF CARBON FIBRE PRECURSOR}

\subsection{Oiling by using the oil roller}

In the precursor oiling control system using oil roller, a porous oiling roller is used. When the carbon fibre precursor passes under the oiling roller, the finish oil first enters the oiling roller and then flows out of the hole of the oiling roller. Then, as the fibre precursor passes through the oiling roller, the finish oil shall adhere to the oil roller; the oil without adhering to the carbon fibre precursor shall flow into the oil groove. Afterwards, the oil circulation pump circulates the finish oil and maintains the oil temperature to prevent oil deterioration. The amount of finish oil in the oil groove is controlled by the metering pump, and the speed of the oil roller is controlled by the inverter, so the oil amount will change with the speed change of the oil roller. Fig.1 depicts the specific control and flow chart, where $\mathrm{S} 802 \mathrm{~B} 3$ is an oil roller.

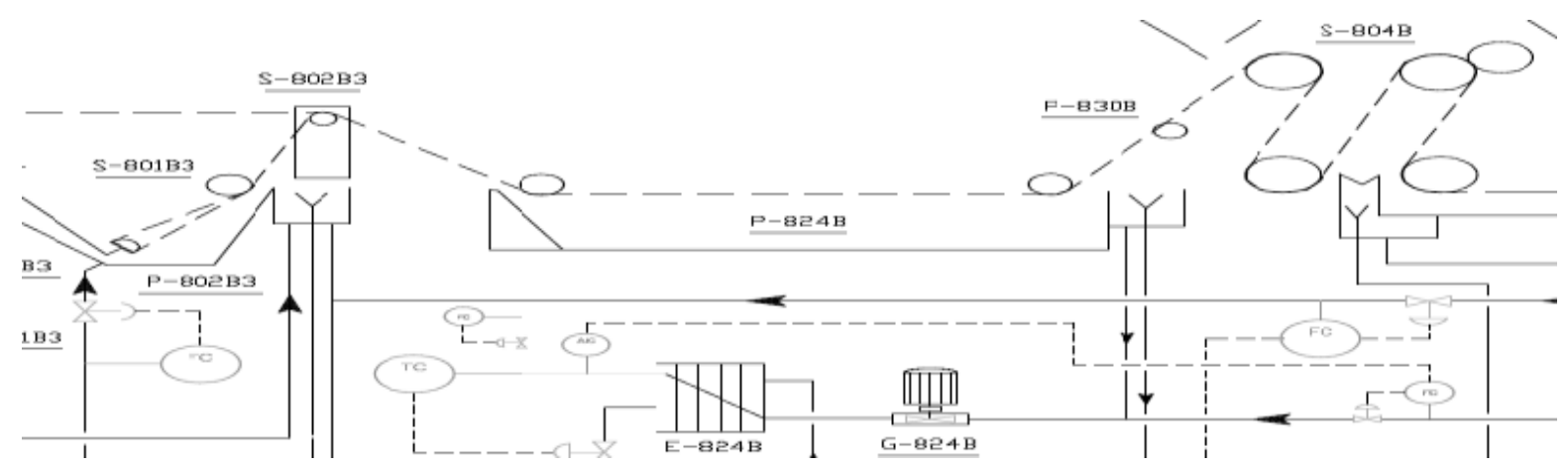

Figure 1: Oiling by using the oil roller 


\subsection{Oiling by using circulation pump of oil groove}

The carbon fibre precursor travels on the oil groove and enters the drying process through the spinning guide roller. The carbon fibre precursor that has passed through the oil groove is completely immersed in the finish oil of the oil groove to realize the full contact between the carbon fibre precursor and the finish oil, and further achieve the purpose of carbon fibre precursor oiling evenly. The oil level of oil tank achieves the liquid level balance through flooding. The oil above the liquid level enters into the circulation tank below the oil groove and is circulated through the circulation pump to maintain the oil temperature and prevent oil deterioration. Besides, the oil concentration in the oil groove should be inspected periodically to ensure that the required oil concentration for production is prepared. The concentration of the finish oil in the oil groove is continuously adjusted by the circulation pump, because the circulation pump can keep the oil concentration in the oil groove stable, when the carbon fibre precursor passing through the oil groove can gradually dilute the concentration. This process control method has only one oil circulation pump, with no need for frequency conversion control; the oil concentration control can be made by the ratio of the finish oil and the water. The control process is simple, and the operation is relatively stable (Fig.2). In this oiling method, the main equipment such as oil groove, circulation tank and circulation pump are applied.

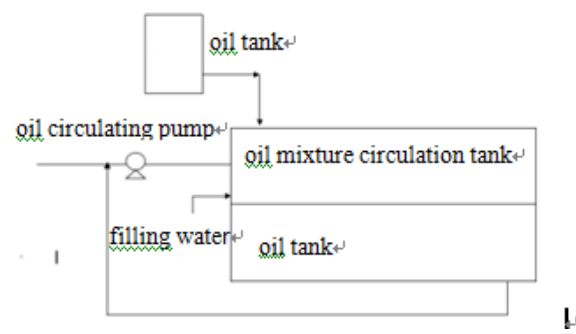

Figure 2: Oiling process by using circulation pump of oiling groove

\section{PROBLEMS WITH CARBON FIBRE PRECURSORS OILING}

3.1 Effect analysis of oil roller oiling process on the production cost and quality of carbon fibre

Table 1 lists the oil content and related test indexes of carbon fibre precursors product.

Table 1: Precursors product test using oil roller

\begin{tabular}{|c|c|c|c|c|c|c|c|}
\hline \begin{tabular}{|l} 
Strand \\
Density
\end{tabular} & $\begin{array}{l}\text { Finenes } \\
\text { s } \\
\text { (Instru } \\
\text { ment) }\end{array}$ & $\begin{array}{l}\text { Denier } \\
\text { CV\% }\end{array}$ & Streng & $\begin{array}{l}\text { hStrengt } \\
\text { CV\% }\end{array}$ & $\begin{array}{l}\text { hElonga } \\
\text { on } \%\end{array}$ & $\begin{array}{l}\text { i Elongati } \\
\text { on CV\% }\end{array}$ & $\begin{array}{l}\text { i Oil } \\
\text { content } \\
\text { CV\% }\end{array}$ \\
\hline 1.430 & 1.23 & 7.98 & 6.49 & 9.60 & 11 & 7.97 & 1.17 \\
\hline 1.416 & 1.22 & 7.75 & 6.35 & 10.10 & 11 & 7.19 & 1.15 \\
\hline 1.430 & 1.24 & 7.23 & 5.83 & 16.70 & 11 & 9.81 & 1.12 \\
\hline 1.432 & 1.24 & 7.88 & 6.35 & 8.40 & 10 & 6.07 & 1.21 \\
\hline 1.432 & 1.23 & 7.97 & 6.48 & 14.07 & 11 & 12.37 & 1.22 \\
\hline
\end{tabular}

\subsection{Analysis of oiling process data using oil roller}

In the test data table, it's found that the $\mathrm{cv}$ value of the carbon fibre precursor produced through this process control method is not satisfactory. Therefore, the production process and control were studied and analysed, to find that the advantages of this production process were even oiling, while the disadvantages are shown as follows:

(1) Despite the even oiling of this oiling control process, due to the unsmooth oiling roller, the problem of carbon fibre precursors curling around the roller during the production process seriously affects the production yield of the carbon fibre precursor.

(2) It is difficult for head-up at the beginning of production, because the carbon fibre precursor needs to pass through the bottom of the oiling roller, but there is an oil tank at the bottom. This greatly reduces the head up speed and wastes a lot of raw liquid, resulting in great waste and higher production cost
(3) The winded roller is difficult to handle, which influences the high-speed running time, thereby affecting the production cost. Also, the roller winding and strand breaking can decrease the overall strength of the carbon fibre precursor.

(4) Since the oil tank is too deep, the oil can easily deteriorate increasing the cost of raw material, and further the production and operation cost of the carbon fibre precursor.

(5) There are high requirements for the smoothness of the oil roller passing through the carbon fibre precursor, so the processing process is difficult. Increasing the smoothness of the oil roller shall result in higher processing cost, but the non-smooth oil roller shall lead to the broken filament, which affects the strength and quality of carbon fibre.

3.3 Effect of oiling method using the oil pump of oil groove on production cost and quality of carbon fibre precursor

Table 2: Precursor test for oiling process by using the oil pump of oil groove

\begin{tabular}{|c|c|c|c|c|c|c|c|}
\hline $\begin{array}{l}\text { Strand } \\
\text { Density }\end{array}$ & $\begin{array}{l}\text { Finenes } \\
\text { s } \\
\text { (Instru } \\
\text { ment) } \\
\end{array}$ & $\begin{array}{l}\text { Denier } \\
\text { CV\% }\end{array}$ & Stre & $\begin{array}{l}\text { CV\% } \\
\text { Ctren }\end{array}$ & $\begin{array}{c}\text { nElong } \\
\text { on \% }\end{array}$ & $\begin{array}{l}\text { Elonga } \\
\text { on CV\% }\end{array}$ & $\begin{array}{l}\text { content } \\
\text { CV\% }\end{array}$ \\
\hline 1.430 & 1.21 & 8.21 & 6.98 & 4.60 & 11 & 3.30 & 1.28 \\
\hline 1.441 & 1.17 & 8.22 & 7.05 & 3.98 & 11 & 3.72 & 1.18 \\
\hline 1.448 & 1.11 & 8.09 & 6.72 & 4.37 & 11 & 3.33 & 1.25 \\
\hline 1433 & 1.18 & 7.82 & 6.96 & 3.97 & 11 & 4.36 & 1.24 \\
\hline 1.462 & 1.31 & 8.17 & 6.51 & 3.88 & 11 & 3.55 & 1.27 \\
\hline
\end{tabular}

\subsubsection{Advantages and disadvantages of oiling process using the oil pump of oil groove}

This control process method does not result in roller winding, having no influence on the spinning speed. In addition, it does not increase the leadup time, so as to reduce wear, increase production, and decrease the production costs. However, this control process can increase the usage amount of oil, resulting in higher raw material consumption cost and production cost. But, per calculation, the overall cost is reduced, and the integrated production cost of carbon fibre precursors is reduced by $0.7 \%$. Besides, this control process also improves the quality of the carbon fibre precursor, because it doesn't scratch the strand, which eliminates the possibility of broken filaments. The reduction of broken filaments can ensure to enhance the carbonization strength of the carbon fibre precursor and improve the quality of carbon fibre.

\subsubsection{Improvement to be made}

The cost of the finish oil accounts for $15 \%$ of the whole production cost of the carbon fibre precursor. In order to further reduce the cost, it is necessary to reduce the oil amount for circulation in the oiling process.

\section{IMPROVED METHOD FOR OILING PROCESS OF CARBON FIBRE PRECURSORS}

\subsection{Improved method}

In view of the above disadvantages, the improvement and optimization test were conducted in this process. First, the equipment was finished to reduce the phenomenon of the winding roller and improve the high-speed production time so that the effect of roller-winding and speed-reduction on the production yield is reduced and the output is improved. Secondly, to reduce the head-up time and the loss rate of raw liquids, the improved method should be made by changing the position of the oil roller. However, in this production process, the oil roller is designed to be immersed in the oil tank, while the distance between the oil roller and oil tank is hard to change. Thirdly, for reducing the possibility of oil deterioration, the method of reducing the depth of the oiling groove was adopted, but it is faced with the same problem that at least one third of the oiling roller must be immersed in the oil tank, so the circulation amount of the oil still has no big change, and the cost index is still very high, with the oil cost accounting for $12.7 \%$ of the total production cost of carbon fibre precursors. 


\subsection{Improved oiling control system}

Multiple precursors of carbon fibre are oiled in the oil groove, and the oiled precursors are guided to the spinning line drying system via a godet roller. The oil level of oil tank is maintained by flooding, and the oil concentration is controlled by detecting the concentration of circulating oil in real time, to ensure the uniformity and stability of oil. Also, the oil in the oil groove is circulated through the circulation pump. The finish oil configuration is mainly performed by using the oil groove, and the addition amount of oil is controlled by the installed control valve. The amount added depends on the concentration of the oil on the circulation tube. Before improving the oiling control system, the oil usage and circulation amount were required to be 2.5 tons. After adding the oil tank in real-time control, the oil circulation amount was reduced to 1.3 tons. In this way, the oil is added in real time by cancelling the circulation tank, and the amount of refilled oil is just the amount of oil taken by the carbon fibre precursors, so as to greatly reduce the filled amount, the amount of oil circulation, and the deterioration of oil. Thus, the cost of oil control in the carbon fibre precursor production is reduced; the usage cost of oil agent decreases to be $7.5 \%$ by improving the oiling process control. Fig. 3 depicts the oiling process control.

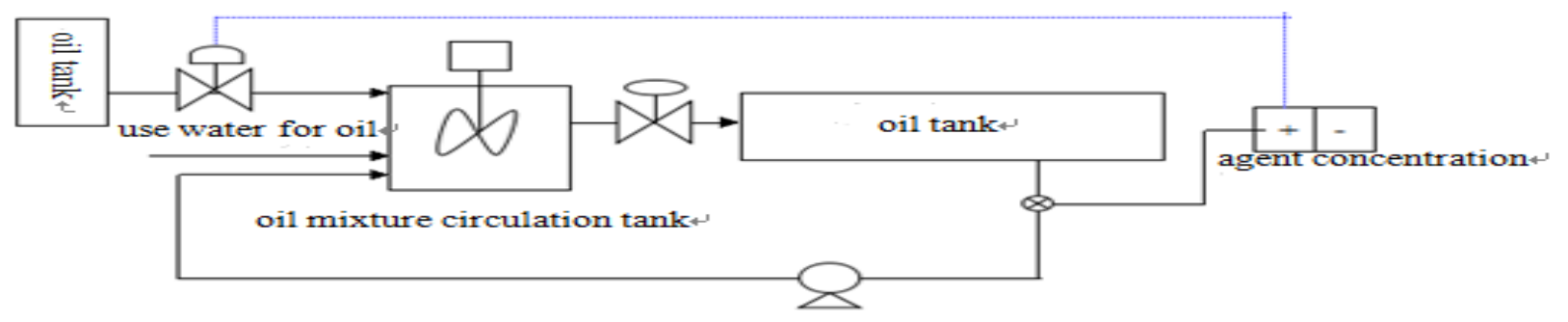

Figure 3: Oiling process by using the oil tank of oil groove

\section{IMPROVING RESULTS OF OILING METHOD FOR CARBON FIBRE PRECURSORS}

Table 3: Precursor test in the oiling process using the oil tank of oil groove

\begin{tabular}{|c|c|c|c|c|c|c|c|}
\hline $\begin{array}{l}\text { Strand } \\
\text { Density }\end{array}$ & $\begin{array}{l}\text { Finenes } \\
\text { (Instru } \\
\text { ment) }\end{array}$ & $\begin{array}{l}\text { sDenier } \\
\text { CV\% }\end{array}$ & Stren & $\begin{array}{l}\text { Stren } \\
\text { CV\% }\end{array}$ & $\begin{array}{l}\text { Elong } \\
\text { on \% }\end{array}$ & $\begin{array}{l}\text { Elongati } \\
\text { on CV\% }\end{array}$ & $\begin{array}{l}\text { Oil } \\
\text { content } \\
\mathrm{CV} \%\end{array}$ \\
\hline 1.430 & 1.27 & 8.26 & 6.98 & 4.60 & 11 & 2.30 & 1.20 \\
\hline 1.441 & 1.17 & 7.22 & 7.05 & 3.98 & 11 & 2.72 & 1.18 \\
\hline 1.448 & 1.21 & 5.99 & 6.72 & 4.37 & 11 & 3.33 & 1.21 \\
\hline 1.433 & 1.18 & 8.42 & 6.96 & 5.36 & 11 & 3.36 & 1.23 \\
\hline 1.444 & 1.14 & 6.39 & 6.99 & 4.22 & 11 & 3.16 & 1.21 \\
\hline
\end{tabular}

\subsection{Precursors cost and quality analysis for the improved oiling process}

It can be seen in Table 3 that the oil content and related test indexes of carbon fibre precursors haven't been influenced; the oil amount used for circulation is halved, and the workers' labour also is reduced. It is analysed in detail as follows:

(1) The finish oil in the circulation tank does not need to be manually removed every time the equipment stops, or the oil deteriorates, which reduces the waste, the original production cost of the carbon fibre, and the labour workload of the employees. Before, when equipping stopping or oil deterioration, 2 employees were required to load the finish oil of oil groove and oil circulation tank 10 vats, which could take about 1 to 2 hours cleaning time;

(2) There is no undermixing, thus producing no effect on the uniformity of the oil concentration, and improving the production quality of the carbon fibre precursor;

(3) The concentration of finish oil can be controlled timely, so as to increase the uniformity of oiling, and improve the quality of carbon fibre precursor.

\section{CONCLUSION}

Excellent oil control methods, with good oil proportioning, and experienced operator, reduce the adverse effects of oil on carbon fibre precursors, solve the oil defects of carbon fibre precursors, and reliably improve the performance indicators and property of carbon fibre precursors; the reliable oiling control make the oiling achieve an ideal oiling effect, ensuring the stability, continuity and homogeneity of various indicators in the production of carbon fibre precursors. At present, the finish oil in China is imported, and the control process is also very simple, resulting in great oil consumption and waste. If the oil control process is promoted, the quality and performance of the domestic oil will be improved accordingly. In the future, the cost of carbon fibre precursors will further be reduced under the premise of ensuring quality, finally occupy the entire domestic market and replace the imported carbon fibre products.

\section{REFERENCES}

[1] Huang, D.M. 2017. Analysis of oiling effect of polyacrylonitrile carbon fiber precursor. Hi-Tech Fiber and Application, 42 (6), 30-32.

[2] Muhammad Mansoor Shaikh, Awadh O. AlSuhaimi, Marlia M. Hanafiah, Muhammad Aqeel Ashraf, Ahad Fantoukh, Eman AlHarbi. 2017. Leachable Volatile Organic Compounds from Polyethylene Plumbing Plastic Pipes: A case study of Medina Al Munawarah, Saudi Arabia. Acta Chemica Malaysia, $1(1), 01-03$.

[3] Cho, T.J. 2017. Innovative Micro-Dust Reduction Technologies. Acta Chemica Malaysia, 1 (1), 04-07.

[4] Yuan, Y.H. 2013. Study on Oiling Process of Polyacrylonitrile-based Carbon Fiber Precursor. Technology Economics in Petrochemicals, 29 (5), $39-41$.

[5] Yuan, Y.H. 2015. Analysis on Causes of Strand of Precursor for PAN based Carbon Fiber Technology and Economics in Petrochemicals, (3), 3538.

[6] Wang, X.C. 2011. The Analysis for End Breaking during Production of PAN Precursor. Hi-Tech Fiber and Application 36 (4), 38. 